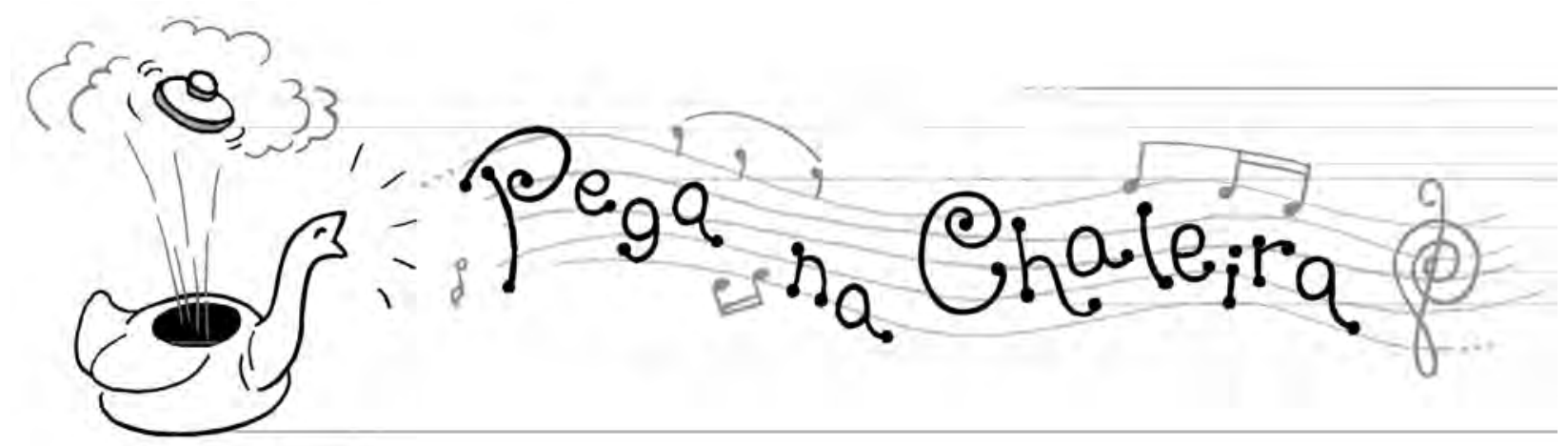

PEGA NA CHALEIRA - RESENHAS

\title{
Resenha: Bossa Nova e Crítica de Liliana Harb Bollos
}

\author{
Carlos Ernest Dias (UFMG, Belo Horizonte, MG)
}

carlosed@uol.com.br

\section{Review: Bossa Nova e crítica [Bossa Nova and criticism] by Liliana Harb Bollos}

BOLLOS, Liliana Harb. Bossa Nova e crítica: polifonia de vozes na imprensa. São Paulo: Annablume, 2010; Rio de Janeiro: Funarte, 2010. 263 páginas. $\mathrm{R} \$ 31,50$

O livro Bossa Nova e Crítica - polifonia de vozes na imprensa, de Liliana Bollos, traz uma importante contribuição aos estudos sobre a Música Popular Brasileira. 0 trabalho analisa as publicações críticas sobre a Bossa Nova, colhidas em arquivos do IEB - Instituto de Estudos Brasileiros, do Suplemento Literário do jornal 0 Estado de São Paulo, da revista Clima e sobretudo do Arquivo Tinhorão no Instituto Moreira Sales. 0 volume, originado na tese de doutorado da pesquisadora, estabelece relações entre a História e a Arte, colocando a hipótese de que a crítica musical no Brasil evoluiu a partir dos moldes da crítica literária. Para demonstrar isso, o primeiro capítulo discorre sobre a formação da literatura brasileira e também de sua crítica, explorando obras de Silvio Romero, Machado de Assis e Sérgio Buarque de Holanda. Essa análise permite ao leitor acompanhar a evolução do pensamento crítico no campo da literatura, mas que incidirão, segundo a autora, diretamente sobre a crítica musical erudita e posteriormente sobre a música popular. Liliana justifica a permanência de Mário de Andrade como figura central na gênese de uma crítica musical baseada na linguagem artística e não em elementos extrínsecos a ela, contrapondo-se à crítica historiográfica de cunho social estimulada por Silvio Romero, que ganhou hegemonia na passagem do século XIX para o século XX.

Percorrendo trilhas abertas por José Miguel Wisnik em " 0 Coro dos Contrários" (1983) e por Bruno Kiefer em "Villa Lobos e o Modernismo na Música Brasileira" (1986), o primeiro capítulo analisa as movimentações ocorridas na Semana de Arte Moderna e as polêmicas por ela provocadas na imprensa, incluindo o famoso confronto entre o conservador Oscar Guanabarino e o modernista Menotti Del Picchia. 0 texto pontua a importância das revistas Klaxon (1922-23) e Ariel, (1922-24) que, após a Semana, passaram a publicar artigos e produções de caráter educativo, com a participação de vários colaboradores. 
A autora menciona a importância das pesquisas sobre músicas brasileiras publicadas por Mário de Andrade em diversos livros, mas mantém o foco do trabalho na análise de sua produção crítica em jornais e revistas. Acompanhando a evolução e a conformação de uma crítica musical que oscila entre a crítica ideológica e a crítica estética, Liliana explora a ampla influência do escritor e musicólogo sobre a intelectualidade musical da primeira metade do século XX. Conceitos amplamente discutidos no meio acadêmico musical brasileiro, a identidade nacional e o caráter interessado da arte brasileira desenvolvidos por Andrade permeiam a discussão na segunda metade do primeiro capítulo. Mas o foco principal da pesquisa é mesmo o campo da crítica e do jornalismo musical, ou seja, na análise intrínseca do objeto musical, sem o cunho social e historiográfico que marcaram o projeto nacionalista. Analisando as dicções e contradições do intelectual no período, o texto investiga as forças presentes em seu trabalho como critico de música e no seu compromisso de promover uma instrução e um "amelhoramento" ${ }^{1}$ do brasileiro.

O livro Bossa Nova e Crítica historiciza o lugar da crítica e o diálogo entre a universidade e a imprensa na interpretação crítica do contexto cultural brasileiro. Valendo-se do livro Papéis Colados, de Flora Sussekind, Liliana descreve os dois modelos de crítica que se contrapõem a partir dos anos 1940: a crítica de rodapé, escrita por bacharéis e jornalistas, e a crítica universitária, desenvolvida por membros da Academia. Antônio Cândido em São Paulo e Afrânio Coutinho no Rio de Janeiro são os dois nomes mais significativos no segundo modelo, e que viriam a promover um estreitamento de laços entre a crítica universitária e os suplementos literários dos jornais, entre a literatura de invenção e a grande imprensa. Os trabalhos de Cândido e Coutinho localizam-se no período de afirmação do modernismo, quando se avalia a produção surgida entre os anos 20 e 40. Os dois intelectuais pavimentam o caminho para a chegada do movimento concretista em São Paulo nos anos 50, em cujo âmbito se revela a produção dos "poetas-críticos", entre eles Décio Pignatari e os irmãos Augusto e Haroldo de Campos.

A Revista Clima, publicada entre 1941 e 1944, e que teve Mário de Andrade como patrono, foi, segundo a autora, o ponto de partida de uma bem sucedida trajetória de intelectuais ligados à Faculdade de Filosofia da USP, que estabeleceriam uma estreita relação com a sociedade através da publicação de artigos e críticas nos principais jornais do país. 0 texto aponta ainda as turbulências provocadas pela ditadura militar no ambiente universitário a partir de 1964, quando muitos suplementos literários foram fechados, ocasionando um afastamento e uma reclusão da universidade com relação ao contexto cultural.

0 segundo capítulo do livro inicia abordando as origens da crítica musical e a sua evolução enquanto ramo jornalístico e propagador da cultura. A seção permite ao leitor conhecer as etapas vividas pela música popular brasileira no século $X X$, através da análise de minuciosos dados sobre gravações e críticas publicadas no período. 0 capítulo percorre uma vasta bibliografia, que inclui os principais especialistas em música brasileira, como Lúcio Rangel, Jairo Severiano, José Ramos Tinhorão, José Miguel Wisnik, Hermano Vianna, Carlos Sandroni, Santuza Cambraia Naves, Arthur Nestrovski e Tárik de Souza.

Liliana Bollos destaca a publicação de revistas sobre música popular como elemento fundamental no processo de reconhecimento da produção existente nas rádios brasileiras. A autora analisa publicações como PhonoArte (1928 a 1931), PRA Nove (1938), Radiolândia, ( 1953 a 1963), e principalmente a Revista da Música Popular, dirigida por Lúcio Rangel e publicada entre 1954 e 1958. Segundo a autora, é na Revista da Música Popular, considerada por Tárik de Souza como a "bossa nova" da imprensa musical no Brasil, que a informação e a discussão sobre música popular ganha corpo e um acalorado espaço para discussão. A professora promove em seu trabalho uma interessante comparação entre os perfis da Revista Clima e da Revista da Música Popular. Enquanto na primeira todos os colaboradores são provenientes da universidade e buscavam a construção de um pensamento crítico unilateral, na segunda encontram-se os mais diferentes tipos de colaboradores, gerando uma polifonia de vozes, que apesar de algumas dissonâncias, dialogam entre si.

0 texto chama a atenção para novos fatos sócio-culturais que se dão no país nos anos 50 , como a polarização entre o estímulo ao desenvolvimentismo urbano dos anos JK e as novas leituras sobre a cultura popular de origem rural, surgidas com as obras de João Cabral de Mello Neto e Guimarães Rosa. Por outro lado, as transformações ocorridas no cenário econômico do Estado Novo iriam influenciar os comportamentos das elites brasileiras nesse período, provocando mudanças nos hábitos de consumo, incluindo a TV, o rádio e os gêneros "modernos" por eles propagados. Entre os pontos abordados, está a influência que a bossa nova, um gênero essencialmente moderno, teria sofrido do jazz, sobretudo do cool jazz, tido como um gênero moderno e sutilmente revolucionário. 0 livro apresenta minuciosos dados sobre alguns dos principais discos lançados no período e que influenciaram 0 aparecimento da bossa nova. Entre eles, estão The Birth of the Cool de Miles Davis (1949), Julie is her name, da cantora Julie London com o guitarrista Barney Kessel, Canção do Amor Demais, de Jobim e Vinicius (1958), e Chega de Saudade de João Gilberto (1959).

Colocada a ideia de que a música popular brasileira atinge a sua maioridade com a Bossa Nova, o texto esboça uma visão de que as proposições do nacionalismo andradiano irão se concretizar no campo da música popular, e não mais na música erudita. Essa "fratura" do nacionalismo na música erudita, por volta de 1950, vem sendo apontada por diversos pesquisadores da música brasileira, entre eles 
o compositor e pianista Celso Mojola, cujo depoimento oral é citado pela autora (pág. 130). Este considera o caso de Cláudio Santoro, compositor que explorou em sua obra os conceitos nacionalistas, mas que ao compor as Canções de Amor com Vinícius de Moraes em 1955, estaria "passando o bastão" do nacionalismo para Jobim, sem que este soubesse propriamente disso. Alternando entre opiniões próprias e descrições técnicas dos discos e a maneira como estes foram concebidos, gravados e recebidos pelo mercado, a autora contribui com a discussão sobre a influência do jazz e sobre a retomada do samba pela bossa nova, ainda que estes temas já estejam bastante explorados na bibliografia sobre o gênero.

0 terceiro e último capítulo, no qual a autora analisa a recepção da bossa nova pela imprensa, define três momentos pontuais da crítica sobre o novo gênero: a recepção do disco Canção do Amor Demais, lançado em 1958, as críticas imediatamente subsequentes ao Concerto do Carnegie Hall em novembro de 1962, e um último momento no qual, já consolidada a bossa nova, há uma crítica mais cuidadosa e menos tendenciosa sobre 0 assunto, e que permite uma compreensão maior da música em si. Como exemplo disso a autora cita a crítica "Canções de Modinhas Nossas", de José da Veiga Oliveira, sobre a qual desenvolve extensa análise. Publicada no Suplemento Literário do Estado de São Paulo em 28/02/1959, é a única crítica sobre música popular publicada naquele periódico. Liliana concentra sua análise na dificuldade exposta pelo crítico em definir se aquela música seria popular ou erudita. Essa discussão encontra lugar na obra de Antônio Carlos Jobim, tido por muitos como herdeiro de Villa-Lobos em vários aspectos de sua escrita musical.

Realizando um extenso e exaustivo levantamento de críticas sobre música em geral, mas concentrando-se naquelas sobre a bossa nova, o texto de Liliana Bollos apresenta um caráter quase investigativo sobre o assunto, e percorre os principais debates e polêmicas sobre o impacto que a bossa nova causou tanto no meio musical quanto no meio jornalístico. A autora mostra como as críticas sobre música se polarizaram entre as críticas acadêmicas publicadas no Suplemento Literário ou na Revista Clima e entre as críticas sobre música popular escritas nas revistas comerciais. A questão das influências jazz/bossa nova/jazz é novamente objeto de análise, demonstrando o quanto o assunto esteve em discussão, provocando tensões e incompreensões.

Uma das relevantes contribuições deste trabalho é o minucioso levantamento de críticas publicadas na imprensa sobre um evento até então coberto de obscuridades. Tratase do Concerto de Bossa Nova no Carnegie Hall em Nova Yorque, em novembro de 1962. Tendo coletado e analisado vinte e duas críticas sobre o assunto, Bollos elucida de forma definitiva para o leitor como se deram os fatos daquele show, demonstrando também a tendência negativa da crítica brasileira com relação ao evento. Envolvendo as principais figuras da música popular no Brasil e nos Estados Unidos, como o letrista Ray Gilbert, o compositor e arranjador Clare Fischer, além dos músicos Stan Getz, João Gilberto, Gerry Mulligan e Tom Jobim, o livro apresenta em detalhes todas as tensões e movimentações comerciais geradas por aquele momento de "exportação" da bossa nova. A importância do show para a música brasileira no exterior é revelada de forma isenta, através do confronto entre diversas críticas e opiniões, evitando-se os preconceitos existentes no Brasil, explicitados por alguns pesquisadores brasileiros.

0 trabalho de Liliana Bollos contribui também para 0 conhecimento dos principais livros sobre música popular publicados nos anos 60, durante o calor da discussão sobre nacionalismos e estrangeirismos. Entre esses livros, estão Panorama da Música Popular Brasileira, de Ary Vasconcelos, de 1964, Música Popular: um tema em debate, de José Ramos Tinhorão, lançado em 1966 e o clássico Balanço da Bossa, de Augusto de Campos, lançado em 1968. Outras tendências são também contextualizadas, como a tendência nacionalista e participante desenvolvida pelos Centros Populares de Cultura da UNE e a retomada do samba tradicional por interpretes como João Gilberto. Embora se concentre na questão da crítica musical e na recepção da bossa nova pela imprensa e pela crítica, o livro possibilita o contato com um amplo painel histórico sobre a música popular brasileira do século $\mathrm{XX}$, com riqueza de detalhes sobre os seus protagonistas e sobre as principais gravações e publicações, críticas ou não, sobre esta música.

Reafirmando a hipótese que as leituras críticas sobre música popular tiveram origem no campo da literatura, 0 livro propicia o conhecimento das diversas interpretações que o fenômeno da música popular gerou ao longo do período, seja na crítica promovida pelas revistas comerciais, quanto na crítica mais especializada e mais acadêmica. Nessa última, a autora destaca o trabalho de Augusto de Campos, que agregou em torno de si um grupo de escritores, músicos e maestros que desenvolveram a ideia de uma crítica "de invenção" e de cunho estético. Não apenas intelectuais, mas conhecedores da linguagem musical, e que por isso mesmo puderam desenvolver um amplo debate, como se vê no livro Balanço da Bossa, referência obrigatória para qualquer estudioso da música brasileira no período em questão. Por sua vez, o livro de Tinhorão explicita uma visão conservadora e não progressista, presa a padrões nacionalistas e avessos a influências estrangeiras nos ritmos nacionais.

0 estudo de Liliana Harb Bollos sobre a crítica musical em torno da Bossa Nova vai bem além das proposições iniciais. Se for verdade que os estudos sobre o Modernismo Musical no Brasil vêm se tornando cada vez maiores, ainda são poucos os autores que tratam o assunto de forma metódica e isenta de preconceitos como neste trabalho. A autora presta toda a sua reverência a Mario de Andrade, mas consegue relativizar o alcance de suas projeções sobre a cultura musical brasileira, seja por avançar no período cronológico, indo até a Bossa Nova, seja por tratar esse 
gênero como algo realizador das propostas do modernismo musical brasileiro, só que no campo da música popular e não mais no campo da música de concerto. Nesse sentido, são extremamente elucidadoras as abordagens de aspectos presentes no gênero, como a relação entre a poesia e a música, entre a cultura e o mercado, entre o local e o estrangeiro e entre a música erudita e a popular.

A autora enxerga pontos em comum nos trabalhos de Mário de Andrade e de Augusto de Campos. Para a professora, ambos procuram legar à música seus elementos inerentes, Mário pela construção, Augusto pela invenção (pág. 240). Bollos considera ainda que entre Mário de Andrade e a Bossa Nova, houve a formação de uma crítica moderna brasileira, que passa por Antonio Candido e Afrânio Coutinho, pela Revista Clima, pelo Suplemento Literário do jornal 0 Estado de São Paulo e pela "invenção" do grupo Noigandres, formado pelos concretistas sob a inspiração de Oswald de Andrade.

A autora termina o seu trabalho manifestando sua preocupação quanto a não existência de uma crítica que reconheça a música popular como fenômeno artístico em primeiro lugar, para depois inseri-la num ambiente ideológico ou sociológico, e que acabam quase sempre caindo nas recorrentes análises sobre os nacionalismos musicais.

Tendo a concordar com Liliana que necessitamos urgente de estudar, conhecer e superar as dicotomias do século
$X X$, uma vez que já estamos na segunda década do século $X X I$ e outros impasses se anunciam, que certamente envolverão tanto a produção musical quanto a produção textual e crítica sobre música.

Carlos Ernest Dias é Professor de Oboé, História da Música Popular e Música e Modernismo na Escola de Música da UFMG, tendo se graduado com o Mestrado em Ciência da Arte pela UFF (com a dissertação Antônio Carlos Jobim: imagens e relações em Matita-Perê e Águas de Março, 2004) e o Bacharelado em Oboé pela UFMG. Estudou oboé com Vaclav Vineck, Luis Carlos Justi, Ricardo Rodrigues e Afrânio Lacerda e foi oboísta da Orquestra Sinfônica de Minas Gerais, do Teatro Nacional de Brasília e da Orquestra Sinfônica Brasileira no Rio de Janeiro. Coordenou o Festival de Inverno da UFMG (1993-1998), a Banda Sinfônica da UFMG (2004-2008), - I Encontro de Estudos da Música popular Brasileira (2006), e diversos projetos de extensão. Com o CD Imagem (Karmim, 1999) recebeu o Troféu Pró-Música de Minas Gerais na categoria Melhor Arranjador. Foi curador da série Cartografia Musical Brasileira em MG (Rumos Itaú Cultural Música 2000/2001). Participou de shows e gravações com Juarez Moreira, Marcus Viana e Marco Antônio Guimarães. Foi o arranjador e instrumentista (oboé, corne inglês e flauta) do CD Ode Descontínua e Remota para Flauta e Oboé de Zeca Baleiro e Hilda Hilst (2005). Atualmente, é Chefe do Depto. de Instrumentos e Canto da Escola de Música da UFMG.

\section{Nota}

1 Expressão de Mário de Andrade, citada pela autora.

Carlos Ernest Dias é Professor Assistente da Escola de Música da UFMG, onde ministra as disciplinas Oboé, História da Música Popular e Modernismo e Música Brasileira. Integrou a Orquestra Sinfônica de Minas Gerais, a Orquestra do Teatro Nacional de Brasília e a Orquestra Sinfônica Brasileira. Possui Mestrado em Ciência da Arte pela UFF, Graduação em Oboé pela UFMG e, atualmente, cursa o Doutorado em Música na UFMG. Na música popular, atua como instrumentista (oboé e saxofone), compositor e arranjador, tendo gravado o CDs Imagem (1999) que recebeu o Troféu Pró-Música de Minas Gerais na categoria melhor arranjador. Foi curador da série Cartografia Musical Brasileira (Rumos Itaú Cultural Música 2000 e 2001). Coordenou o Festival de Inverno da UFMG (de 1993 a 1998), a Banda Sinfônica da UFMG (de 2004 a 2008) e o I Encontro de Estudos da Música Popular Brasileira (2006). Atualmente é Chefe do Departamento de Instrumentos e Canto (2011 a 2013). 